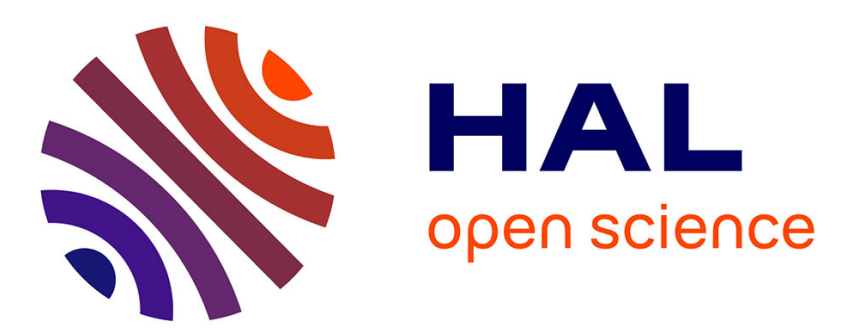

\title{
Lack of correlation between ex vivo apical dye penetration and presence of apical radiolucencies
}

Guy Susini, Ludovic Pommel, Imad About, Jean Camps

\section{To cite this version:}

Guy Susini, Ludovic Pommel, Imad About, Jean Camps. Lack of correlation between ex vivo apical dye penetration and presence of apical radiolucencies. Oral Surgery, Oral Medicine, Oral Pathology, Oral Radiology and Endodontology, 2006, 102 (3), pp.e19-e23. 10.1016/j.tripleo.2006.03.015 . hal03552256

\section{HAL Id: hal-03552256 \\ https://hal.science/hal-03552256}

Submitted on 2 Feb 2022

HAL is a multi-disciplinary open access archive for the deposit and dissemination of scientific research documents, whether they are published or not. The documents may come from teaching and research institutions in France or abroad, or from public or private research centers.
L'archive ouverte pluridisciplinaire HAL, est destinée au dépôt et à la diffusion de documents scientifiques de niveau recherche, publiés ou non, émanant des établissements d'enseignement et de recherche français ou étrangers, des laboratoires publics ou privés. 


\title{
Lack of correlation between ex vivo apical dye penetration and presence of apical radiolucencies
}

\author{
Guy Susini, DCD, PhD, ${ }^{\mathrm{a}}$ Ludovic Pommel, DCD, ${ }^{\mathrm{a}}$ Imad About, PhD, ${ }^{\mathrm{b}}$ and \\ Jean Camps, DCD, PhD, ${ }^{\mathrm{a}}$ Marseille, France \\ UNIVERSITÉ DE LA MÉDITERRANÉE
}

\begin{abstract}
Objective. The aim of this study was to determine if there is a significant correlation between the in vivo presence of periapical radiolucency and ex vivo apical dye penetration on the same human teeth.

Study design. Eighty-four endodontically filled teeth that were scheduled for extraction were classified into 2 groups according to the presence or absence of a periapical radiolucency and further divided into 2 subgroups according to the quality of the root canal filling. After extraction, the apical filling was evaluated by a dye penetration method.

Results. The dye extraction evaluation showed no correlation between apical dye penetration and the presence of a periapical radiolucency (not significant), but a statistically significant correlation with the quality of the root canal filling $(P=.03)$.

Conclusion. The results of the dye penetration study were correlated to the quality of the root canal filling but had no predictivevaluefor the developmentof periapical radiolucency.
\end{abstract}

The importance of the coronal seal for periapical health of endodontically treated teeth has been underestimated for many years, recently emphasized, ${ }^{1}$ but more recently questioned. ${ }^{2}$ Its importance is considered subordinate to that of the apical seal because only an impervious apical seal can prevent bacteria, from either endodontic origin or from the oral cavity, to reach the apex. Therefore, the apical seal would seem to be the key to any successful endodontic treatment because it allows both sealing of any bacteria entrapped within the root canal, and prevents the influx of periapical tissue fluid from entering the canal to provide nutrients for intracanal bacteria. Dye penetration studies only evaluate the potential for very small diluted dye molecules to diffuse into a canal but do not measure the possibility for bacterial leakage from the root canal into the periapical region.

Nevertheless, the apical sealing efficiency of various techniques and materials have been extensively evaluated. Many in vitro techniques have been developed for this purpose but can give contradictory results, and their findings are often questioned. ${ }^{3}$ Some studies have compared the techniques themselves showing conflict- ing results as well as the influence of the technique on the outcome of the study. ${ }^{4}$ Without any clinical standards, leakage comparisons themselves are questionable. It is difficult to know whether the most clinically relevant leakage method is the most discriminatory technique, or if this technique is too sensitive and points out significant differences that do not have clinical significance. When developing a new test to assess biocompatibility of materials, it is common to use materials with a known clinical history. This enables comparison between the outcome of the test and published literature to evaluate the clinical significance of the test. In line with this idea, using endodontically treated teeth scheduled for extraction might provide important specimens for an apical dye penetration study.

The purpose of this study was to compare ex vivo apical dye penetration of teeth, with or without periapical radiolucencies, with the clinical status of the tested teeth, using a volumetric dye penetration method.

\section{MATERIALS AND METHODS}

\section{Tooth preparation}

Human monoradicular teeth were used for this work $(\mathrm{n}=105)$. The teeth were extracted for various reasons (e.g., periodontal and prosthodontic reasons) that were not related to the study, in order to represent a cross-section of teeth with root canal treatment. The age of root canal filling was recorded to only include teeth endodontically treated at least 4 years before the extraction to allow for radiographic signs of outcome of treatment. ${ }^{5}$ These teeth presented no sign of periapical pathosis at the time of 
endodontic treatment. Only teeth with restorations of good quality, alpha and beta ratings from US Public Health Service criteria ${ }^{6}$ were included in the study, in order to reduce the associated factors such as the quality of the coronal seal. A periapical radiograph was taken prior to extraction and examined by two endodontists trained in using the periapical index. ${ }^{7}$ The teeth were then divided into 2 groups: those with a periapical radiolucency visible on the radiograph (periapical index $\geq 4$ ) and those without visible radiolucency (periapical index $<4$ ). Some small bony lesions within cancellous bone are not radiographically detectable. Therefore, some teeth presented soft tissue adherent to the apex, which could be a periapical lesion, that was not preliminarily detected by the presence of a radiolucency on the radiograph. These teeth were discarded to eliminate the false negative periapical lesions $(n=12)$. The crowns were removed at the cementoenamel junction and the extracted teeth were stored in $0.5 \%$ chloramine solution at $4^{\circ} \mathrm{C}$ until use. They were scaled to remove any remnant of soft tissue, taking care not to disturb the apex, before examination under a binocular microscope at a magnification of $\times 9.5$ to eliminate roots with artifactual fracture or cracks as a result of the extraction with forceps $(n=9)$. Finally, 84 teeth were included in the study. Two radiographs in the mesio-distal and in the bucco-lingual direction were taken. Two trained endodontists radiographically determined the extent and the density of the root canal filling. The teeth were then divided into 2 subgroups: dense filling, without voids, within $2 \mathrm{~mm}$ of the apex (well filled) $(\mathrm{n}=52)$, and nondense filling, or with voids, or filling shorter than $2 \mathrm{~mm}$ of the apex (poorly filled) $(\mathrm{n}=32)$. The teeth were labeled accordingly.

\section{Dye extraction study}

Preliminary study. Dye penetration tests can be made quantitative by dissolving dye taken up by filled roots in 65\% nitric acid according to the method of Douglas and Zakariasen. ${ }^{8}$ The optical density (OD) of various dilutions of $0.5 \%$ buffered methylene blue dye in $65 \%$ nitric acid was measured. Each well of a 96well plate received $190 \mu \mathrm{L}$ of $65 \%$ nitric acid, except for the wells of the first column that were left empty. The wells of the second column received $10 \mu \mathrm{L}$ more nitric acid to calibrate the instrument. The wells of the other columns received $10 \mu \mathrm{L}$ of serial dilutions of $1 \%$ methylene blue dye: $1 / 1,1 / 2,1 / 4,1 / 8,1 / 16,1 / 32,1 / 64$, and $1 / 128$. The plates were gently shaken to mix the color. The OD was measured immediately after shaking, and again at 1 day, 3 days, and 7 days. The plates

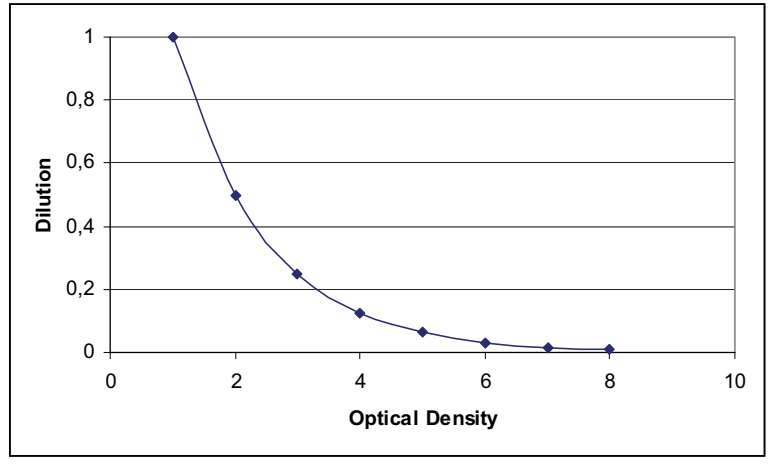

Fig 1. Correlation between the OD and the dilution of methylene blue dye in nitric acid, stored for 7 days in a dark place, recorded with a 550-nm wavelength $(\mathrm{y}=-0.255 \operatorname{Ln}(\mathrm{x})+$ 0.4523 and $\mathrm{R}^{2}=0.9498$ ).

were stored in a dark place between measurements.

The OD was recorded with a spectrophotometer (E 960j Bioblock, Strasbourg, France) using different wavelengths: $405,450,490,550,600$, and $650 \mathrm{~nm}$.

A statistical linear relationship was sought between the OD of the liquid and methylene blue concentration, using the method of the least squares. The confidence level was set at $5 \%$. Regardless of the methylene blue dye concentration, the wavelength used for the study, or the storage time, statistically significant linear correlations were found between methylene blue dye concentration and the OD of nitric acid dye standards. Because the highest correlation coefficient values $\left(\mathrm{R}^{2}\right)$ were obtained at a wavelength of $550 \mathrm{~nm}$, that wavelength was used for the dye penetration study (Fig. 1).

Dye penetration study. The roots of extracted endodontically treated teeth were covered with nail varnish except for the most apical $2 \mathrm{~mm}$ and were immersed in $0.5 \%$ neutral methylene blue dye $(\mathrm{pH}=7)$ under negative pressure. To establish a vacuum, the roots were placed in an empty flask connected with a vacuum pump (Neuberger, Freiburg, Germany). After establishing a vacuum for 10 minutes (negative pressure 600 $\mathrm{mm} \mathrm{Hg}$ ), the air outlet was closed with a valve. A second valve connected to a vial filled with the methylene blue dye solution was opened releasing the dye solution into the flask without allowing air to enter into the vacuum system. The roots remained submerged in methylene blue dye for another 10 minutes to ensure removal of any air from gaps within the filled roots. The roots were transferred in vials containing the same dye solution at normal atmospheric pressure so that the apex touched the dye solution. They were stored for 7 days to allow dye penetration by capillarity. The teeth were then removed from the dye solution, rinsed under tap water for 30 minutes, and any external dye residue 
Table I. Repartition of the 84 teeth according to the presence or absence of a periapical radiolucency as well as of the quality of root canal filling, n (\%)

\begin{tabular}{lccr}
\hline & Well-filled & Poorly-filled & Total \\
\hline $\begin{array}{l}\text { Presence of apical } \\
\text { radiolucency }\end{array}$ & $20(24)$ & $15(18)$ & $35(42)$ \\
$\begin{array}{l}\text { Absence of apical } \\
\text { radiolucency }\end{array}$ & $32(38)$ & $17(20)$ & $49(58)$ \\
Total & $52(62)$ & $32(38)$ & $84(100)$ \\
\hline
\end{tabular}

was removed when the nail varnish was removed with a scalpel. The roots were stored in a sealed vial containing $600 \mu \mathrm{L}$ of concentrated (65 wt\%) nitric acid for 3 days to allow for complete dissolution of the roots and extraction of the dye. The vials were then centrifuged at $14,000 \mathrm{rpm}$ for 5 minutes to separate guttapercha debris and the organic components from the extracted dye. From each vial, $200 \mu \mathrm{L}$ of the supernatant was taken and transferred to a 96-well plate. The absorbance of the 96-well plate was determined using an automatic microplate spectrophotometer, at $550 \mathrm{~nm}$, using concentrated nitric acid as the blank, as previously described. The OD of each well represented the amount of methylene blue dye that penetrated the apex of the corresponding root.

\section{Controls}

Negative controls were used to test the ability of varnish to keep dye out of the roots and positive controls were used to evaluate the ability of the dye to completely invade an empty root. Thirty additional intact single-rooted teeth, extracted for periodontal reasons, were used for these controls. The crowns were removed at the cementoenamel junction with a diamond disk under water coolant. A \#10 K file was introduced into the canal to radiographically measure the working length and to check the patency of the apex for apical dye penetration. The root canals were prepared by the same operator at the cementodentinal junction with a ProFile device (Maillefer, Ballaigues, Switzerland) using a reduction handpiece powered by an electric motor following the sequence: ProFile taper 06 \#30, \#25 and \#20; ProFile taper 04 \#25 and \#20; ProFile taper $06 \# 20$, \#25, and \#30. A \#10 K file was used between each ProFile to verify the apex patency. Two milliliters of $2.5 \% \mathrm{NaOCl}$ irrigant, delivered with a 27-gauge needle, was used between each file size.

The 30 teeth were then randomly divided into 2 groups. Fifteen teeth were used as negative control and were filled with gutta-percha using the lateral condensation technique and a zinc oxide-eugenol based sealer (Cortisomol; Pierre Rolland, Merignac, France). These
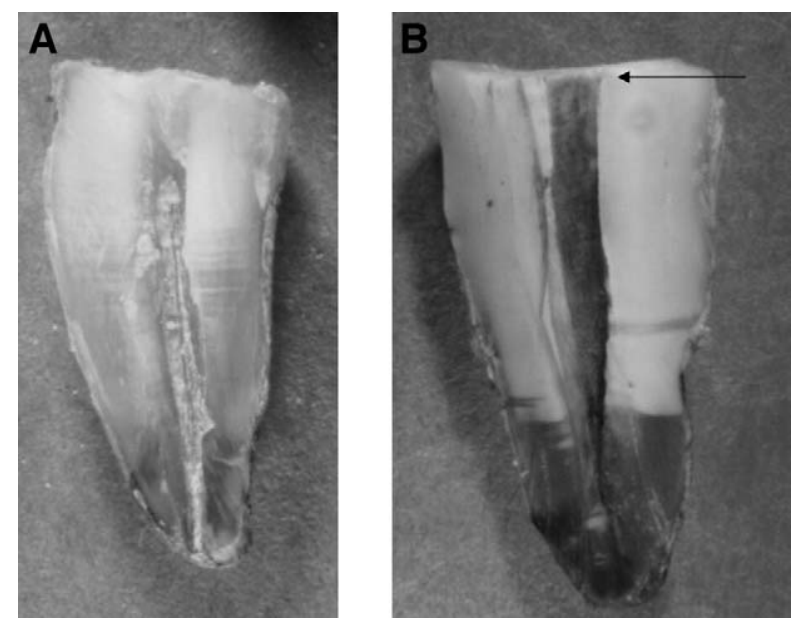

Fig 2. Additional teeth used as negative control (A) and positive control (B) split into 2 halves. The filling material of the negative control was removed to show the absence of dye penetration. The positive control shows a complete dye penetration of the empty root (arrow).

15 teeth were then stored for 1 day in an incubator at $37^{\circ} \mathrm{C}$ and $100 \%$ humidity to allow setting of the endodontic sealers. These roots were completely covered with varnish. The other 15 teeth were used for positive control and were cleaned and prepared but not filled. The teeth were exposed to methylene blue dye exactly as previously described.

\section{Statistical analysis}

Two nonparametric Mann-Whitney tests were successively performed to compare the groups with or without periapical radiolucency and the groups with well and poorly filled roots. The confidence level was set at $5 \%$.

\section{RESULTS}

A summary of the results of the experimental 84 teeth is given in Table I. The negative control showed no dye penetration owing to sealing of the apex by the varnish (Fig. 2). In contrast, positive controls showed a high OD $(3.25 \pm 0.74)$. The first Mann-Whitney test failed to show a statistically significant difference between the groups with or without a periapical lesion (not significant) (Table II). The second test showed a statistically significant difference between the wellfilled and poorly-filled groups $(P=.03)$.

\section{DISCUSSION}

The purpose of dye penetration studies is to rank various sealers or filling techniques in comparison to each other prior to their introduction to clinical prac- 
Table II. Optical density after dye extraction (mean \pm $\mathrm{SD})$ of the 4 groups*

\begin{tabular}{lccc}
\hline & Well-filled & $\begin{array}{c}\text { Poorly- } \\
\text { filled }\end{array}$ & Mean $\pm S D$ \\
\hline $\begin{array}{c}\text { Presence of apical } \\
\text { radiolucency }\end{array}$ & $1.17 \pm 0.89$ & $1.74 \pm 1.90$ & $1.41 \pm 1.30$ \\
& & & $\mathrm{~ns}$ \\
$\begin{array}{c}\text { Absence of apical } \\
\text { radiolucency }\end{array}$ & $1.46 \pm 0.80$ & $1.22 \pm 0.90$ & $1.37 \pm 0.89$ \\
Mean \pm SD & $1.34 \pm 0.85$ & $1.62 \pm 1.30$ & \\
\hline
\end{tabular}

$n s$, Not significant.

*The analysis of variance failed to show a statistical difference between the 2 groups with or without periapical lesion (not significant) but showed a significant difference between the well-filled and poorly-filled groups $(P=.03)$.

tice. However, the question remains as to whether these comparisons are clinically relevant or not. In the current study, apical dye penetration had no predictive value in determining the presence of a periapical radiolucency (not significant). Nevertheless, this work showed higher apical dye penetration in teeth with a poor root canal filling than in teeth with good root canal filling $(P=.03)$. Under the conditions of this study, limited by a modest sample size owing to strict criteria of inclusion, this means that apical dye penetration studies can give us an idea of the quality of the root canal filling but not of the success of the endodontic filling.

In a study by Oliver and Abbott, ${ }^{9}$ in vitro and ex vivo dye leakage results were compared on extracted human teeth. The teeth were divided into 2 groups: successful and unsuccessful endodontic treatments. Linear apical dye penetration was measured on the extracted teeth and the results of both groups were compared. The results showed no difference in apical dye leakage between the 2 groups. The authors concluded that dye penetration study was not clinically relevant because the successful and unsuccessful endodontic treatments showed the same degree of apical dye penetration. Their conclusions only apply to their study. First, they measured linear dye penetration technique to record the quality of the apical seal. This method is not very reliable because the axis of cutting is randomly chosen and only reaches the deepest dye penetration by chance. ${ }^{3}$ Second, the authors constructed 2 groups of teeth according to the success or not of the endodontic treatment without evaluating the radiographic quality of the root canal filling.

The dye extraction technique, used in the current study, involves recovering all of the dye that penetrated the apex, thereby avoiding the limitations of sectioning the root. The results of linear dye penetration studies indicate the length of the longest void along a root filling, whereas those of volumetric dye penetration, first described by Douglas and Zakariasen, ${ }^{8}$ provide information on the total volume of all voids. Despite contradictory results, the results of volumetric dye penetration studies are theoretically more relevant. ${ }^{10} \mathrm{In}$ addition, it has been demonstrated that the depth of dye penetration is not uniform around the margins of a composite restoration. ${ }^{11}$ If the same phenomenon occurs during the dye evaluation of endodontic fillings, the linear dye penetration method is not suitable for evaluating apical leakage because the cutting axis is randomly chosen, thus making the probability that the section occurs through the deepest dye penetration very low. Once cut, the root filling can obviously be removed to look for dye in other plans. However, this technique only enables evaluation of the dentin-sealer interface, not of the sealer-gutta-percha interface or that of sealer voids. The results of volumetric dye penetration, reported here, are similar to those of fluid filtration, another volumetric study measuring technique. $^{3}$

The variations in OD observed over time indicate that methylene blue does slowly react with nitric acid. However, these changes never lead to a loss of statistical linear correlation between OD and methylene blue dye concentration. According to the present study, the assumption that methylene blue dye reacts with nitric acid over time to change gradually to a green color $^{12}$ is not valid. The correlation between methylene blue dye concentration in nitric acid and OD remained valid for 7 days. For apical leakage evaluations, this means that the roots can be stored in $65 \%$ nitric acid for up to 7 days, until dissolution of the root is complete. Because the correlation coefficients between OD and methylene blue dye concentration varies with time and wavelength, it would be wise to establish this relationship in each experimental protocol before any new study is undertaken.

In this work, the roots were submitted to vacuum before dipping into the methylene blue dye. This step is necessary to remove the air bubbles entrapped within the filling material that can prevent dye penetration. ${ }^{13} \mathrm{~A}$ pilot study with a limited number of teeth was necessary to adjust the pressure and the time. A neutral methylene blue dye solution was used to prevent the effect of an acidic solution on the filling material during storage. ${ }^{14}$

The results of this study indicate that factors other than apical leakage play a role in the success or failure of endodontic treatment, such as the virulence of bacteria present within the root canal ${ }^{15}$ or the colonization of the outside cemental surface. ${ }^{16}$

Careful analysis of extracted endodontically treated teeth provides the opportunity to test these speculations 
using fresh specimens. Such posttreatment analyses can provide much needed information if they are done under controlled conditions. This work corroborated the results by Oliver and Abbott, ${ }^{9}$ another study based on extracted endodontically filled teeth, and showed a lack of correlation between apical dye penetration and presence of periapical radiolucencies.

\section{REFERENCES}

1. Ray HA, Trope M. Periapical status of endodontically treated teeth in relation to the technical quality of the root filling and the coronal restoration. Int Endod J 1995;28:12-8.

2. Ricucci D, Bergenholz G. Bacterial status in root-filled teeth exposed to the oral environment by loss of restoration and fracture or caries - a histobacteriological study of treated cases. Int Endod J 2003;36:787-802.

3. Camps J, Pashley D. Reliability of dye penetration studies. J Endod 2003;29:583-5.

4. Pommel L, Jacquot B, Camps J. Lack of correlation among three methods for evaluation of apical leakage. $\mathrm{J}$ Endod 2001;27:347-50.

5. Orstavik D. Time-course and risk analyses of the development of chronic apical periodontitis in man. Int Endod J 1996;29:150-5.

6. Hayashi M, Wilson NH, Watts DC. Quality of marginal adaptation of posterior composites in clinical trials. J Dent Res 2003;82:59-63.

7. Orstavik D, Kerekes K, Eriksen HM. The periapical index: a scoring system for radiographic assessment of apical periodontitis. Endod Dent Traumatol 1986:2:20-34.

8. Douglas WH, Zakariasen U. Volumetric assessment of apical leakage utilizing a spectro-photometric dye recovery method. J Dent Res 1981;60:438-43.

9. Oliver CM, Abbott PV. Correlation between clinical success and apical dye penetration. Int Endod J 2001;34:637-44.

10. Madison S, Zakariasen KL. Linear and volumetric analysis of apical leakage in teeth prepared for posts. $\mathrm{J}$ Endod 1984;10:422-7.

11. Gale MS, Darwell BW. Dentine permeability and tracer tests. J Dent 1999;27:1-11.

12. Vassiliadis L, liolios E, Kouvas V, Economides N. Effect of smear layer on coronal microleakage. Oral Surg Oral Med Oral Pathol Oral Radiol Endod 1996;82:315-20.

13. Spangberg LSW, Acierno TG, Yongbum Cha B. Influence of entrapped air on the accuracy of leakage studies using dye penetration methods. J Endod 1989;15:548-51.

14. Starkey DL, Anderson RW, Pashley DH. An evaluation of the effect of methylene blue dye $\mathrm{pH}$ on apical leakage. J Endod 1993;19:435-9.

15. Olsen I, Dahlen G. Salient factors in anareobic bacteria with emphasis on their importance in endodontic infections. Endod Topics 2004;9:15-26.

16. Tronstad L, Barnett F, Cervone F. Periapical bacterial plaque in teeth refractory to endodontic treatment. Endod Dent Traumatol 1990;6:73-7. 